$\infty$

0

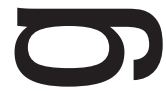

-

ת

1

$\longrightarrow$ 



\title{
GEOTECNOLOGIAS APLICADAS À REESTRUTURAÇÃO FUNDIÁRIA
}

\author{
RESTRUCTURING THE APPLIED GEOLAND
}

\author{
Paulo Roberto Lopes Thiers - UFC \\ pthiers@ufc.br \\ Antônio Jeovah Andrade de Meireles - UFC \\ meireles@ufc.br
}

\section{RESUMO}

A resolução das questões fundiária e agrária do país passa, necessariamente, pela forma de destinação de terras e por modelo consolidado por políticas públicas que garantam as condições para o uso da terra: registro do imóvel, implantação de infra-estrutura econômica e assistência técnica, saúde e educação para o desenvolvimento social e ambiental viáveis e sustentáveis. As geotecnologias são ferramentas que permitem coletar dados e produzir as informações para a gestão territorial com vistas na reestruturação fundiária.

Palavras-chave: geotecnologias, reestruturação fundiária, SIG.

\begin{abstract}
The resolution of the subjects fundiária and agrarian of the country it passes, necessarily, for the form of destination of lands and for model consolidated by public politics that guarantee the conditions for the use of the earth: registration of the property, implantation of economical infrastructure and technical attendance, health and education for the social and environmental development viable and you sustained. The geotecnologias are tools that allow to collect data and to produce the information for the territorial administration with views to the restructuring fundiária.
\end{abstract}

Key-words: geotecnologias, restructuring, SIG 



\section{Introdução}

As geotecnologias, a nanotecnologia e a microbiologia despontam, segundo pesquisa recentemente divulgada nos Estados Unidos, como as ciências que apresentam as perspectivas mais promissoras de crescimento de mercado de trabalho. As geotecnologias, aqui compreendidas pelo Sistema de Satélites para Navegação Global (GNSS), pelos Sistemas de Informações Geográficas (SIG) e pelo Sensoriamento Remoto a nível orbital e aéreo, são ferramentas utilizadas na coleta de dados e produção de informações para estudo e gestão do espaço.

O processo de concentração fundiária no Brasil teve início no período colonial, em que uma minoria privilegiada se beneficiou do regime de sesmarias, e onde a pecuária e a cana de açúcar constituíram-se em fatores de acentuação do processo de formação de imensos latifúndios.

Hoje em dia o regime latifundiário, como um todo, está em conflito com o nível atingido pelas forças produtivas, assumiu caráter parasitário e é o maior responsável pelos bolsões de pobreza absoluta no meio rural (MIRAD, 1987, p. 9).

A formação da pequena propriedade se desenvolveu com a decomposição do sistema latifundiário, depois de três séculos do descobrimento, com a chegada dos imigrantes europeus, na chamada colonização estrangeira no Sul do Brasil. Segue-se o processo de criação de pequenas e médias empresas com a Lei Imperial de 1848, que concedia áreas territoriais para colonização.

A Lei 601, de 18 de setembro de 1850, chamada Lei das Terras Devolutas, representou o primeiro esforço no sentido de discipilnar o direito agrário no Brasil. Proibiu a ocupação de terras devolutas, só admitindo a compra mediante pagamento em dinheiro. Permitiu a revalidação das sesmarias que se mantivessem cultivadas ou com princípios de cultura e fossem morada habitual do sesmeiro, do concessionário ou de seu representante. Com tudo isso, objetivava duplamente, coibir os inconvenientes do regime de sesmarias e permitir a consolidação legal das posses. (Borges, 1984, p.16)

O acesso à terra constitui-se, objetivamente, no primeiro passo para a resolução das questões fundiária e agrária do país. A forma de destinação de terras para resolução das questões agrária e fundiária deve ser estabelecida consoante modelo, consolidado por políticas públicas que garantam as con- 
dições para o uso da terra: registro do imóvel, implantação de infra-estrutura econômica e assistência técnica, saúde e educação, para o desenvolvimento social e ambiental viável e sustentável.

\section{Reestruturação Fundiária}

A reestruturação fundiária é um redesenho de uma situação fundiária. É o mecanismo que se utiliza de diagnósticos fundiários gerados a partir de informações produzidas com características geométricas, posicionais, jurídicas, sócio-econômicas e ambientais de imóveis rurais e seus ocupantes, para solução de questões relacionadas às questões fundiária e agrária. O diagnóstico fundiário serve de orientação à tomada de decisão sobre qual modalidade deve ser utilizada no processo de reestruturação fundiária: reorganização, redistribuição ou regularização fundiárias.

\section{Redistribuição fundiária da terra}

A redistribuição fundiária é a aquisição de imóveis pelo Estado através da compra ou venda, desapropriação ou arrecadação do devoluto apurado, e tem o objetivo de reduzir e impedir o fluxo migratório de trabalhadores rurais para os centros urbanos. As geotecnologias possuem ferramentas para a identificação das áreas consideradas ociosas, seus verdadeiros tamanhos e efetiva utilização.

A identificação de áreas para reestruturação fundiária é feita com informações geográficas produzidas por posicionamento terrestre por satélites (GNSS), pela utilização de técnicas de processamento digital de imagens (LANDSAT, QuickBird, Ikonos, SPOT, CBERS2, CBERS2B, GEOEYE1 e outras) e por análise e consulta espaciais em SIG, para informar os tipos de solo, o uso e ocupação atual, dimensões reais dos imóveis, recursos hídricos superficiais, condições de acesso e infraestrutura.

\section{Reorganização fundiária}

A identificação de concentração de minifúndios na base de dados digital permite a implementação de ações para alterar a forma de exploração desses minifúndios. A identificação das áreas de latifúndios que exercem 
pressão social sobre esses minifúndios pode ser utilizada para a reorganização fundiária, com fins de melhoria na qualidade de vida das pessoas.

\section{Regularização fundiária}

A regularização fundiária identifica os imóveis que se encontram sob simples ocupação (sem registro de imóvel), através de operação cadastral. Na operação cadastral são levantadas as características gráficas (geometria) e não-gráficas (identificação do imóvel e detentor, capacidade de produção agrícola, etc.) dos imóveis rurais. Para a regularização fundiária é formulado um processo para a arrecadação do devoluto apurado e concessão de título de domínio às posses identificadas.

\section{Separação de bens público e privado}

A Ação Discriminatória é a base de sustentação jurídica do processo de construção do cadastro de imóveis, e envolve ações que provêm a separação entre o público e o privado. Discriminar significa identificar e arrecadar as terras devolutas. Para tanto, uma comissão especial de discriminação é criada para proceder à caracterização jurídica dos imóveis.

As informações e dados obtidos na operação cadastral e a caracterização jurídica dos imóveis rurais são inseridos na base de dados digitais, estruturada em software de SIG, compreendendo:

- $\quad$ geometria das feições gráficas relativas aos perímetros dos imóveis rurais;

- banco de dados com atributos e valores de atributos relativos às benfeitorias, condição jurídica e outras características de importância para suporte à construção do diagnóstico fundiário.

\section{Combate à grilagem com Informações Geográficas}

As geotecnologias são ferramentas valiosas no combate à grilagem de terras, identificando o correto posicionamento geográfico do imóvel rural, a sua geometria e a identificação de suas reais características dominiais. 
A grilagem é um dos mais poderosos instrumentos de domínio e concentração fundiária no meio rural brasileiro. Em todo o país, o total de terras sob suspeita de serem griladas é de aproximadamente 100 milhões de hectares, quatro vezes a área do Estado de São Paulo ou a área da América Central mais México (INCRA, 1999, p.8).

... corresponde à ação ilegal com fins de transferir terras públicas para o patrimônio de terceiros, implementada por conivência dos cartórios de registros imobiliários, que registram áreas sobrepostas umas às outras, ou seja, elas só existem no papel” (INCRA, 1999, p. 12).

O Pontal do Paranapanema, no ano de 1998, foi área de atuação do Instituto de Colonização e Reforma Agrária - INCRA, que se utilizou de receptores geodésicos do sistema GNSS e imagens de satélites LANDSAT, para vistoriar 191 propriedades, em cinco municípios. O resultado obtido concluiu que a área potencial identificada para reforma agrária, após conclusão dos trabalhos foi de 37\%, contra 19\% da área total, antes do referido levantamento. "Essa é a sentença de morte das fraudes no campo", afirma o eng ${ }^{\circ}$ Milton Santos Amorim/INCRA-BSB(VEJA - 11 de março de 1998, p. 62).

\section{Base de dados digitais}

O cadastro de imóveis rurais ou base de dados digitais é composto da geometria com exata localização geográfica dos imóveis rurais sobre a superfície terrestre e de informações e dados relativos às suas características, armazenadas em banco de dados relacionais.

As informações geográficas produzidas com geotecnologias fornecem o suporte para tomada de decisões em políticas públicas para gestão do território.

A produção sistematizada de informações geográficas utilizadas nos processos de reestruturação fundiária, obtidas por consultas e análises espaciais sobre a base de dados digitais do cadastro de imóveis rurais, permitem fornecer a classificação dos imóveis quanto ao grau de utilização e eficiência na exploração, a função social, a dominialidade, a qualidade das terras e outras características. 


\section{Metodologia para construção da base de dados digitais}

O processo de elaboração da base de dados digitais tem início com a definição da área objeto da ação de reestruturação fundiária sendo, posteriormente, realizada a identificação, o reconhecimento, a análise e o estudo com relação aos aspectos de uso/ocupação, aspectos socioeconômicos, e outros. Esta fase comporta a consulta dos dados/informações na literatura existente, levantamento de campo, análise dos materiais cartográfico e cartorário disponíveis.

A base de dados é produzida, organizada e estruturada para permitir o acesso, o armazenamento e a manipulação dos dados gráficos e descritivos (literais) relativos aos imóveis rurais e ocupantes. A base de dados espaciais é gerada pelo desenvolvimento de ações conjugadas: operação cadastral e ação discriminatória.

Na operação cadastral, levantam-se todas as características gráficas e não-gráficas dos imóveis rurais da área: perímetro (geometria), identificação e qualificação dos detentores dos imóveis, uso atual, aspectos produtivos e tecnológicos de exploração do imóvel, valor das benfeitorias existentes, valor da terra nua e cobertura vegetal em conformidade com os preços de mercado, condição de acessibilidade e qualidade das terras, condição jurídica do imóvel, confrontações e litígios, se esses existirem.

Para o levantamento dos perímetros de imóveis são utilizados modernos receptores geodésicos do sistema GNSS e/ou estações totais, que garantem qualidade geométrica para cumprimento de normas e leis pertinentes (Lei 10.267/01, Normas Técnicas para Georreferenciamento de Imóveis MDA/INCRA e outras).

\section{Modelo de dados}

O processo de estabelecimento do modelo de dados para o SIG deverá envolver, inicialmente, a identificação das entidades do mundo real, seguida pela definição dos respectivos atributos e, por último, o estabelecimento dos relacionamentos entre as entidades.

A identificação de entidades é considerada a fase mais importante num SIG e compreende a identificação da entidade física relacionada à entidade gráfica espacial que a representará na base de dados. Para efetiva implementação, deverá ser adotado o que se segue: identificar com precisão 
as entidades que o mundo real modelado envolve, os seus atributos e os seus relacionamentos; Implementar tabelas para cada entidade, cujos campos são seus atributos; escolher campos comuns (chaves) que permitam implementar os relacionamentos.

\section{Construção do sistema de informações}

O sistema tem como fim produzir informações geográficas para gerar o diagnóstico fundiário e classificar os imóveis quanto a: grau de utilização e eficiência na exploração, função social, dominialidade, qualidade das terras e outras características, permitindo categorizá-los para alvos de aplicação de políticas públicas: redistribuição, reorganização e regularização fundiárias.

A tecnologia SIG suporta uma grande quantidade de definições devido à sua ampla gama de aplicações, onde cada tipo de definição prioriza um aspecto distinto, refletindo a sua interdisciplinaridade (Câmara Neto et al, 1996).

Segundo Aronoff (1992), um SIG pode ser definido como um sistema de informação baseado em computador o qual permite capturar, armazenar, manipular, analisar e exibir dados referenciados espacialmente e associados a atributos, para solução de problemas complexos.

O termo dados geográficos ou objetos georreferenciados é aplicado aos dados utilizados em SIG que descrevem objetos relacionados a fatos e fenômenos associados à sua localização sobre a superfície terrestre. Os dados geográficos podem possuir características não espaciais representadas por atributos descritivos, armazenados em banco de dados, e características temporais que indicam o tempo da coleta dos dados e sua validade (Câmara Neto, 1996).

\section{Edição e tratamento cartográfico da base de dados espaciais}

Para a integração de documentos cartográficos de diferentes fontes no mapeamento digital a ser utilizado para desenvolvimento do SIG, são efetuados procedimentos de edição e tratamento cartográfico necessários: georreferenciamento com transformação de sistemas de projeção cartográfica e datum geodésico, mudança de escala e validação dos dados para eliminação de erros. 


\section{Conexão da geometria de objetos às tabelas do SGBD}

A conexão dos objetos gráficos às tabelas de um Sistema gerenciador de banco de dados, implica em relacionar essas entidades/feições a uma tabela criada num banco de dados do sistema de informação. A entidade gráfica polígono que representa o perímetro de um imóvel, é associada aos registros da tabela de atributos desse imóvel.

A carga no sistema compreende a inserção dos valores dos atributos nas tabelas do usuário criadas no banco de dados e pode ser efetuada por simples inserção, via teclado ou através de aplicativos extratores de dados, que têm a função de extrair informações de bancos de dados existentes.

O estabelecimento de relacionamentos entre entidades do modelo de dados e seus atributos, permitirá ao usuário gerar consultas para produção de informações espaciais. Os resultados das consultas são informações geográficas que podem ser representadas espacialmente ou apresentadas em relatórios personalizados, e fornecem elementos para planejamento de políticas públicas que incluem processos relativos à reestruturação fundiária.

A apresentação das informações geográficas pode ser efetuada via monitor gráfico ou em mídia de papel, através de periféricos de saída: impressora ou traçador gráfico (plotter).

Um mapa pode ser definido como uma representação gráfica do espaço geográfico, em que as características do mundo real foram substituídas por símbolos visuais em reduzidas dimensões. Para Martinelli (1991), os mapas são veículos que utilizam metodologia para representação cartográfica através de linguagem de comunicação. Este processo é realizado em etapas: confecção, uso e entendimento. Para Bertin apud Martinelli (1991), "a cartografia no seu ramo temático, incorpora na representação gráfica uma linguagem constituída pelos homens para reter, compreender e comunicar" (p. 38 ).

\section{Consulta à base de dados}

A consulta à base de dados pretende obter informações espaciais e valores de atributos que atendam a determinadas condições estabelecidas pelo usuário.

Segundo Puebla et al (1999), para operacionalizar buscas e extração de informações em uma base de dados de um SIG são utilizadas duas formas de consultas: 
- $\quad$ Consulta por Atributos: relaciona-se com os valores dos atributos descritivos das feições do mundo real, armazenados no banco de dados do sistema;

- Consulta Espacia:I diz respeito às consultas que envolvem relacionamentos espaciais entre os objetos/feições selecionados.

A produção de uma base de dados envolve procedimentos que dependem de fontes de informações, com características espaciais e temáticas de um fenômeno real.

Para Sendra (2000), existem dois grandes tipos de fontes de dados:

- Fontes de observação direta da realidade: para a captura fiel de seus atributos;

- $\quad$ Fontes de observação indireta da realidade.

Os métodos para observação direta da realidade se utilizam de equipamentos modernos e precisos para levantamentos da informação espacial: estações totais, níveis eletrônicos, receptores dos sistemas GNSS (Estados Unidos), GLONASS (Rússia), GALILEO (Europa) e COMPASS (China).

Já os métodos de observação indireta da realidade, utilizam mapas analógicos de informações temáticas, fotografias aéreas, imagens de satélites, registros tabulares e processos que compreendem:

- Digitalização automática: corresponde à obtenção de arquivos digitais através da vetorização das feições cartográficas apresentadas no formato matricial (raster); o documento cartográfico fonte é submetido a um processo de transformação de formato vetorial analógico para o formato matricial, pela utilização de scanner que possa garantir boa exatidão geométrica;

- Restituição estereofotogramétrica digital: a base de dados é construída através da utilização de estações fotogramétricas digitais, que permitem transformar imagens digitais e fotografias aéreas em elementos vetoriais correspondentes;

- $\quad$ Técnica de sensoriamento remoto: as informações são extraídas de imagens através de simples vetorização ou por tratamento digital para a produção de classificação, por temas, automática de imagens;

- $\quad$ Geração de geometria analiticamente: procedimento mediante o qual constrói-se feições gráficas em um arquivo digital, com as coordenadas $\mathrm{X}, \mathrm{Y}$ e Z que definem as entidades espaciais do mundo real. 


\section{Considerações finais}

A base digital de dados espaciais (mapa) é o resultado de consultas formuladas ao sistema, e são armazéns da informação do espaço geográfico que se usa como fontes de dados para planejamento de políticas agrárias e fundiárias. O mapa é a fase final do trabalho, o meio pelo qual a informação pode ser analisada e reconstruída. É o último comunicado ao usuário e aos tomadores de decisões, que utilizam os conhecimentos nele contidos.

A quantidade de mapas está relacionada com cada consulta formulada ao sistema, que depende do modelo de dados estabelecido. Cada mapa temático poderá gerar relatórios referentes às mesmas consultas formuladas ao sistema.

A base digital de dados espaciais dos imóveis rurais, com modelo de dados referido às demandas da reestruturação fundiária, será utilizada para análises e consultas espaciais, implementadas por aplicativos, para geração de mapas temáticos para diagnósticos fundiários.

O sistema de informações poderá conter interfaces para a produção, manipulação e gerenciamento das informações geográficas geradas.

\section{Referências}

ARONOFF, S. - Geographic Information Systems - A Management Perspective. Ottawa, WDL Publications, 1995.

BORGES, P. A. - A Propriedade Territorial no Brasil e os Caminhos para a Reforma Agrária. In “Os Donos da Terra”. Rio de Janeiro. CODECRI - IBASE. 1983.

CÂMARA, G et al - Anatomia de Sistemas de Informação Geográfica. Campinas, UNICAMP, 1996.

CHRISMAN, N. - Exploring Geographic Information Systems. New York. John Willey \& Sons, 1997.

DeMERS, M. N. - Fundamentals of Geographics Informations Systems. New York. John Willey \& Sons, 1997.

INTERGRAPH. Guia do Usuário. 1995.

MPFDA/INCRA - O Livro Branco da Grilagem de Terras no Brasil. Brasília. 1999.

MIRAD/INCRA - Evolução da Estrutura Agrária do Brasil. Brasília. 1987.

MARTINELLI, M. - Curso de Cartografia Temática. São Paulo, Editora Contexto, 1991.

PUEBLA, J.G. \& G, M.- SIG: Sistemas de Información Geográfica. Madrid, Editora Sintesis, 1999. 
SENDRA, J.B. - Sistemas de Información Geográfica. Madrid, Rialp, 2000.

Paulo Roberto Lopes Thiers - Professor da Universidade Federal do Ceará

Antônio Jeovah Andrade de Meireles - Professor do Departamento de Geografia da UFC e dos programas de pós-graduação em Geografia e Desenvolvimento e Meio Ambiente (PRODEMA).

Recebido para publicação em agosto de 2008

Aceito para publicação em outubro de 2008 